\title{
Derived Knowledge and Lived Experiences of Teachers Working in Resource- Constrained Multilingual Classrooms
}

\author{
Margaret Funke Omidire \\ Department of Educational Psychology, Faculty of Education, University of Pretoria, South \\ Africa
}

ISSN: 2788-6298

DOI: https://doi.org/10.35293/tetfle.v2i1.92

\begin{abstract}
Due to global migration, multilingual classrooms are currently a common feature not just in postcolonial contexts but also in developed economies. The perceived challenges created by multiple languages in single classrooms have been well documented, and all stakeholders have to be involved in finding strategies to overcome these challenges and change perceptions. Using a case study design and sociocultural theory as lens, this study explored the perspectives and experiences of teachers with teaching and learning in resourceconstrained multilingual classrooms. The participants were teachers $(N=67$; female $n=51$; male $n=16$ ) from nine schools in Gauteng Province of South Africa. The findings suggest that the participants were divided in their perceptions and experiences of multilingual classrooms. While some viewed multilingualism as a constraint to effective teaching and learning; others wanted more to be done to accommodate learners. It is evident that teachers prioritise the necessity for pre-service teacher education that focus on teaching pedagogy appropriate for the multilingual context they work in every day. In addition, the teachers emphasised a range of support strategies they currently use. It is argued that structured variations of the teachers' strategies be developed and distance education employed for the professional development of in-service teachers working in multilingual contexts.
\end{abstract}

Keywords: Multilingualism; language, teaching, learning, teachers' experience, distance education 
Volume 2, 2020

\section{Introduction}

The role of teachers in facilitating learning is an important one that cannot be dismissed even with the current advancement of technology and the internet. The derived knowledge and lived experiences of teachers working in multilingual classrooms and the methods used to navigate the challenges in these spaces, whether perceived or real, become pertinent. The narrative of viewing multilingualism as a barrier to learning could be redefined by exploring the wealth of knowledge teachers have in facilitating learning in these environments (Omidire, 2019). Teaching and learning in many sub-Saharan African countries occur within multilingual contexts. Multilingual contexts and policies governing them create complexities in the systems that result in the majority of students striving to be included during lessons across the spectrum from primary and secondary schools to higher institutions. Teachers' language proficiency, classroom participation norms, teaching experience and attitudes towards home languages can all shape how learning transpires. Therefore, interrogating their experiences and learning from that can provide possible solutions to the challenges faced in the learning environment.

\section{Contexts of education}

Education practices in many postcolonial sub-Saharan African countries are conducted within multilingual contexts where the local languages are used in communities alongside English, French or Portuguese that are used as the languages of instruction. Most countries have developed educational policies aimed at ensuring that students are provided with quality education (UNESCO \& UNICEF, 2013), that is, education that would equip students with the competencies and skills they need to function effectively in the world outside the school (Scott, 2015). These competencies ensure that learners develop the attitudes and skills to become critically reflective adults, who are functional members of the societies to which they belong (Ndofirepi, 2012). There are several challenges that truncate the achievement of these goals, and one of them is when language constitutes a barrier to learning. Monar-Lopez and Villar (2018), opine that students are disadvantaged in respect of performing to the best of their abilities when they are taught in a language in which they have limited knowledge or with which they are not familiar with at all. Extenuating factors include the fact that most teachers in these contexts are themselves second or third language users of the language of instruction and are not necessarily the best models. The United Nations Educational, Scientific and Cultural Organisation (UNESCO) (2016, p. 2) furthermore points out that international and regional learning assessments indicate that "when home and school languages differ there is an adverse impact on test scores". An analysis of the Trends in International Mathematics and Science Study (TIMSS) data in Australia clearly indicates that English reading comprehension is an educational challenge, with approximately two-thirds of indigenous students achieving the minimum benchmarks in Mathematics in Grade 8 between 1994/1995 and 2011, while almost $90 \%$ of their non-indigenous peers managed to do so (Thomson, Hillman, Wernert, Schmid, Buckley, \& Munene, 2012). According to UNESCO (2016, p. 6), teachers in Australia

CONTACT: Margaret Funke Omidire Funke.omidire@up.ac.za ORCID: https://orcid.org/0000-0002-5784-7734

This work is licensed under a Creative Commons Attribution 4.0 International License. 
Volume 2, 2020

"have often mistaken language problems for a learning difficulty". This is not unique to Australia.

In the United States of America (USA) for example, indications are that an influx of emigrant families, amongst others (UNESCO, 2016), poses a challenge to attempts aimed at providing the best learning experience possible to bilingual and multilingual students. Statistical estimations are that $14 \%$ of American students speak two or more languages, while English, the language of instruction at school, is not their primary or home language, indicating that the languages they are exposed to at home and at school are different. By implication, the United States finds itself at a crossroad to come up with effective strategies to educate these students, and to support teachers to acquire the new knowledge and skills they would need to face the realities of bilingual or multilingual classrooms (UNESCO, 2016b; Weber, 2014; García \& Sylvan, 2011). Other countries such as the United Kingdom (UK) are also faced with cultural and linguistic diversity issues, resulting in intricate patterns of compounded disadvantages (Dryden-Peterson, 2015; Ouane \& Glanz, 2011). The presence of these migrant families presents unprecedented challenges to both the country's education system and the students. One outcome of this situation could be that teachers become less committed, an attitude which could affect student performance, potentially resulting in early school exit without qualifications. According to Desai (2016) and McKay (2012), students with higher proficiency levels and greater fluency in the language of instruction have the advantage of developing content and language knowledge simultaneously and with less difficulty. Desai (2016) also notes that learners limited or lack of exposure to the English language, coupled with a lack of support at home, contributes to their struggle to grasp the content of subjects taught through English as a medium of instruction. All these shortcomings have an adverse effect on academic performance (Makgato, 2014). Bilingual and multilingual learners often experience great difficulties coping in classes where the teacher is inadequately trained to teach a multilingual class (Agirdag, 2014; Chostelidou, Griva \& Tsakiridou, 2015).

In South Africa, studies have identified that issues relating to the Language in Education Policy (LiEP) contribute to teachers' and students' lack of reading comprehension and critical-analytic thinking in English (Prinsloo, Ramani, Joseph, Mashatole, Lafon, \& Webb, 2015; Spaull, 2015; Van Staden \& Howie, 2010). Evidence from different studies indicate that students whose home language is the language of instruction seem to have an advantage over those who still have to develop their proficiency and reading comprehension skills in the language of learning to an academically functional level (Clegg \& Simpson, 2016; Marin \& Halpern, 2011; Sibomana, 2020). Moreover, students who learn in an additional language have more difficulty coping with the subject content as they are compelled to juggle between acquiring language proficiency while at the same time learning new subject-related content (Makgato, 2014). Success in all learning aspects of the school curriculum requires the building of a "complex network of linguistic understanding" (Omidire, Bouwer, \& Jordaan, 2011, p. 48), posing a challenge to learners who do not have the requisite language skills to succeed in their academic pursuit.

CONTACT: Margaret Funke Omidire Funke.omidire@up.ac.za ORCID: https://orcid.org/0000-0002-5784-7734

This work is licensed under a Creative Commons Attribution 4.0 International License. 
Volume 2, 2020

Teachers in South Africa and in other sub-Saharan African countries conduct their teaching in multilingual and bilingual settings. In this regard, many students would not have a proper linguistic foundation in English literacy, causing them to take a longer time to acquire the threshold level of English language proficiency that would enable them to learn in English. Spaull (2013) attributes students' underachievement, particularly in literacy and English Literature, to a lack of proficiency in English, teachers' having limited or no training in teaching English and failure to accommodate the differences that the learners bring to classrooms, limited knowledge of how to plan classroom tasks to attend to all the learners' needs, and little or no understanding of how to evaluate learning.

From the abovementioned, the challenges of language in education in multilingual contexts are not in doubt. However, teachers who work in these contexts ought to be able to contribute to knowledge generation and inform teacher education and practice based on their experience of teaching and interacting with learners in multilingual classes. More often than not, teachers are at the receiving end of the teaching and learning challenges that occur in school and are sometimes deemed to contribute to the poor achievement of learners for many reasons including the lack of adequate training or limited pedagogical content knowledge. Teachers' perspectives and experience is therefore pertinent in resolving and alleviating the challenges associated with learning.

\section{Training teachers for multilingual classes}

Teacher education in sub-Saharan Africa needs to foreground the training in context-specific strategies that speak to the multilingual nature of the environment. Clegg and Simpson (2016) and Portolés and Martí (2020) highlighted the mismatch between curriculum reforms and training methods for teachers at teacher education institutions or enrichment support services offered by means of ongoing professional development. This mismatch is compounded due to limited awareness and focus on suitable pedagogy for the contexts. Brutt-Griffler (2017) recommended enhanced participation in research which had as aim the discovery of instructional and pedagogical practices. Research is critical and research involving teachers more so. Studies have shown that teachers in the UK indicate inadequate support for teachers teaching in culturally and linguistically diverse classes (Finch, Theakston \& Serratrice, 2018). According to the Chikiwa and Schäfer (2018) teaching additional language students to think beyond recall and memorisation are abilities which could contribute to enhanced economic development and higher literacy levels in sub-Saharan Africa. We argue that teachers need to be properly equipped to carry out this task in their multilingual contexts. For instance, the shift in thinking regarding multilingualism, means that educational researchers have developed pedagogies such as translanguaging and others that view multilingualism as a resource (García \& Kleyn, 2016; Wei, 2011). These shifts in paradigm and ideology should be incorporated in the pre-service training and ongoing teacher professional development and training through distance education.

CONTACT: Margaret Funke Omidire Funke.omidire@up.ac.za ORCID: https://orcid.org/0000-0002-5784-7734

This work is licensed under a Creative Commons Attribution 4.0 International License. 


\section{Distance education for teacher professional development}

Distance education and the inherent use of technology has made it possible to reach in-service teachers even in remote areas. Distance education therefore affords education practitioners the opportunity to incorporate new research findings into the professional development of teachers. Teacher professional development can be described as a process for enhancing and bringing teachers' knowledge and skills up to date to improve teaching and learning. In some instances, professional development targets the attitude of teachers or aims to develop certain strategies (Philipsen, Tondeur, Roblin., Silke, \& Zhu, 2019). Teachers need to keep abreast of new developments/innovations in the field of education and pedagogy. Distance education with online learning programmes has become an invaluable and cost-effective tool for reaching in-service teachers in different contexts (Philipsen et al., 2019). Distance education for teacher professional development is an avenue for challenging teachers to reflect on their pre-service training, their experiences, and the habits, assumptions and beliefs formulated regarding teaching and learning in the course of their careers. Distance education provides the opportunity to move in-service teachers to twenty-first century thinking in terms of current teaching and learning methods and strategies (Richardson \& Alsup, 2015) especially with the shift in knowledge regarding language in education and positive aspects of multilingualism.

\section{Using sociocultural theory as a basis to enhance practice}

The multilingual teaching and learning spaces are fraught with challenges but there are equally success stories that teachers can learn from. Insights can be derived from teachers' experiences in relationship to teaching in multilingual classes, relationship with learners and teachers' interaction with them and the school environment. The study leaned on Vygotsky's sociocultural theory as a framework. The theory posited that there is a close relationship between the use of language as a cultural tool (in social interaction) and the use of language as a psychological tool (for organising our own individual thinking in the socio-cognitive and sociocultural frameworks (Bo, 2015; Philpo, 2015). The role that language plays in learning highlights its importance in pedagogy, indicating the benefits students derive from teachers' use of techniques or guidance strategies aimed at the generation of a common frame of reference for teaching and learning. Mwelwa (2016), whose study was conducted in Zambia, found that an understanding of the value of culture and language was an important scaffolding component enabling teachers and students alike to participate effectively in English discourse in the classroom. Code-switching and translation of concepts into the local languages is sometimes used by teachers during teaching and learning to enhance cognitive development and achieve a deeper understanding of the concepts being taught. In South Africa, Pretorius (2014), whose study was aimed at exploring dysfunctional schools and educators' perceptions of school effectiveness, found that language was a powerful tool for communication in the classroom context and indicated that two factors led to students' underperforming at these

CONTACT: Margaret Funke Omidire Funke.omidire@up.ac.za ORCID: https://orcid.org/0000-0002-5784-7734 
Volume 2, 2020

schools - their lack of proficiency in the English language, and limited home language instruction. In an attempt to overcome this challenge, students were observed shifting between English and other South African languages during classroom discussions, thereby codeswitching and code-mixing. Teachers' voices on their experiences of teaching in these multilingual contexts, their successes and challenges faced are critical to moving the process of developing adequate teaching and learning strategies forward.

\section{Methodology}

The purpose of the study was to explore the experiences of teaching and learning in multilingual classrooms particularly those situated in resource constrained environments. The aim was to present teachers' voices in the debate and conversation regarding teaching and learning in multilingual classes. The problem of language in the teaching and learning space requires input from teachers given that they are directly involved and often blamed for the challenges experienced by learners. Understanding teachers experiences and how they have coped with teaching in these environments could contribute to arriving at lasting solutions and contributing to the limited literature on the subject. The critical question was "what are teachers experiences and perceptions of teaching and learning in multilingual classrooms? The study also aimed to highlight the strategies teachers believed to be effective for teaching and learning in multilingual classes and the challenges they faced when working in these contexts.

The study employed a case study design to explore the experiences and views of teachers with teaching and learning in resource constrained multilingual classrooms. Purposive sampling was used to identify and select the participants who were teachers working multilingual classes. The participants were 67 teachers (female $n=51$; male $n=16$ ) from nine primary schools in the Gauteng Province of South Africa. The years of teaching experience range from two years to 29 years. A researcher developed questionnaire was distributed to teachers with relevant experience teaching in multilingual classrooms. The questionnaire had two sections. The first section had demographic information and questions on a Likert scale. The second section required written responses that required teachers to give extended details on their knowledge, experiences and strategies utilised for teaching and learning.

Data analysis involved coding the data by labelling, categorising and organising the data from the first section of the questionnaire. This generated descriptive results from the data. Thematic analysis was utilised for the second section. The data was transcribed and sorted into categories from which emergent themes were developed.

Institutional ethics approval was obtained for the project and informed consent was obtained from all the participants. The researchers adhered to the guidelines and conditions of the ethics approval. There was no risk of harm to any of the participants.

\section{Results}

CONTACT: Margaret Funke Omidire Funke.omidire@up.ac.za ORCID: https://orcid.org/0000-0002-5784-7734

This work is licensed under a Creative Commons Attribution 4.0 International License. 
Volume 2, 2020

\section{Demographic information}

The majority of the participating teachers were aged between 30 to 60 years. About $76 \%$ of the participants were female and $24 \%$ male. The qualifications ranged from Advanced Certificates in Education (ACE), Bachelor of Education (B.Ed.) to Post Graduate Certificate in Education (PGCE).

The participants taught Grades 4, 5, 6 and 7. In the primary classes, the teachers are responsible for teaching all the subjects to the learners in their class. The class sizes varied. One participant had 30 learners in the class, while the other participants that had between 41 and 58 learners in each class.

The languages represented in the school were all the 11 official languages of South Africa. In addition to those languages, Portuguese, Chinese and lgbo languages were also represented. The language most widely spoken was isiZulu, followed by Sesotho and isiXhosa. The home languages taught in all the schools were isiZulu, Sesotho and English. Afrikaans and English were also offered as first additional languages in the schools. All the teachers categorised their proficiency level in their home languages as "excellent". An overwhelming majority of the learners do not speak English at home.

\section{Conceptualisation of multilingualism}

The participants were able to define multilingualism and multilingual education. Some of their definitions include the ability to; "speak more than one language", "write or speak more than two languages", "use more than two languages for communication", "communicates in more than two languages", "ability to speak multiple languages"

\section{Being equipped to teach in multilingual classes}

Less than $10 \%$ of the participant believed that they were properly equipped to teach in multilingual classes. Some of the participants believed that they require training and support to deal with the multilingual nature of their classes. Many of the participants opined that their knowledge of teaching in multilingual classes was still developing and that they explore options and strategies to see what works. Thus, not taking advantage of the sociocultural theory notion of language as a cultural and psychological tool in the learning process.

The participants' self-evaluation revealed mixed opinions from them regarding their competence to teach in multilingual classrooms. They expressed that though they had teaching qualifications, their training did not prepare them for the pedagogy required to facilitate learning in multilingual classes. About $40 \%$ of the participants believed that they had the skills to teach in multilingual classes as a number of them were very much confident about

CONTACT: Margaret Funke Omidire Funke.omidire@up.ac.za ORCID: https://orcid.org/0000-0002-5784-7734 
Volume 2, 2020

their abilities. About $55 \%$ of them believed that they had no adequate qualification to teach in multilingual classrooms. Their experience could be described as "on the job learning" as one participant put it "I try to develop myself through the learners while trying to support them". These group of participants however agree that they need assistance to optimise the learning in their classes.

\section{How multilingualism affects learners and teaching across the curriculum}

The participants indicated that from their experience, the multilingual nature of their classes had both positive and negative effects on learners and teaching. Essentially, participants stated that the effects on teaching included hinderance of teachers' development as teachers had to focus on learners with no time for personal growth. Furthermore, the language of instruction constituted a barrier as there was usually a lack of understanding of the content. The participants unanimously agreed that attempting to carry everyone along when the majority do not follow the lessons consumes times and makes it difficult to cover each lesson and by implication the whole curriculum.

The participants revealed that the multilingual nature of the classes had some negative effects on the learners. The most mentioned of these effects is lack of vocabulary by both teachers and learners to work in all the languages represented in the classes. Inappropriate use of languages, the struggle to communicate and potential communication breakdown during lessons are a source of concern for teachers. The participants indicated that there is a perception among learners that learning English language is difficult and some learners hate having to learn in English. In addition, participants believe that allowing the use of home languages could lead to learners mixing languages when communicating resulting in the inability to grasp concepts, and challenges in learning and mastery of the language of instruction.

The participants however identified the positive effects on learners. They agreed that once concepts are explained and clarified in home languages, the result was an in-depth knowledge of such concept. This results in motivation for the learners. Better understanding of the content motivates the learners to aim to achieve more. More importantly, where there is understanding of particular home languages, it promotes better communication across board and results in positive attitudes and learners who are confident to interact with others as well as the teachers.

\section{Benefits of multilingualism}

The participants agreed that there are benefits to being multilingual. The benefits included are varied between teachers and learners. The participants expressed that teaching in a multilingual class could lead to teachers learning new languages through their learners. Teachers are also placed in a better position to offer extended explanations of key terminologies or concepts to their learners using code switching. Multilingualism offered

CONTACT: Margaret Funke Omidire Funke.omidire@up.ac.za ORCID: https://orcid.org/0000-0002-5784-7734

This work is licensed under a Creative Commons Attribution 4.0 International License. 
Volume 2, 2020

another opportunity to reach learners who were struggling to cope with subject content and provided additional support for those at risk and alleviated the challenges of language as a barrier to learning. The participants believed that learners who were competent in the use of more than one language were more confident in their approach to their studies. Furthermore, the participants expressed that from their experience, being multilingual facilitates rapport building with colleagues and learners.

\section{Challenges experienced whilst teaching in multilingual classes}

The findings revealed that the participants unanimously agreed that there were multiple challenges associated with teaching in multilingual classroom especially in a situation where there was limited access to the resources and facilities to support teaching and learning in such context.

\section{Ethnocentrism}

The participants opined that from experience the promotion of multilingualism could be challenging due to ethnocentrism as there would be languages that are spoken by majority of learners in any given classroom.

\section{Misuse of time}

Promoting multilingualism was deemed to require significant lengths of time. Participants expressed that there is usually limited time earmarked on the school timetables for each subject and engaging in multilingual activities. They stated that covering the curriculum and associated administrated responsibilities are time consuming and make incorporating additional tasks unrealistic to take on.

\section{Lack of resources}

Participants believed that a major challenge to the introduction and use of multilingualism is resources. They opined that there were not enough books and learning support materials in English, the language of instruction. It is therefore inconceivable that resources will be allocated to the introduction and use of other languages.

\section{Lack of professional development}

Participants opined that from their experience of working in primary schools, the number of teacher professional development programmes available to them was limited. Those presented often do not meet the needs of bringing the teachers up to date and introducing innovative strategies but are largely a recap of policy statements.

CONTACT: Margaret Funke Omidire Funke.omidire@up.ac.za ORCID: https://orcid.org/0000-0002-5784-7734 
Volume 2, 2020

\section{Orthography and language complexities}

The participants explained that the orthography of some of their home languages were yet to be developed for academic use. Translation of terminologies is often difficult; even while trying to implement code switching, some home languages are deemed harder than others. Furthermore, participants explained that their experience has shown that there could also be confusion due to teachers trying to explain in different languages during a single lesson. This could lead to "communication breakdown" according to a participant.

\section{Teachers' linguistic attitudes}

Participants believe that some teachers have a negative attitude towards the use of home language and that such teachers as well as parents want teaching and learning to take place solely in English the language of instruction. The participants emphasised the importance of acknowledging cultural and linguistic diversity and actually finding meaningful ways to celebrate differences among the learners and teachers.

\section{The multilingual teaching strategies learners respond to}

The participants emphasised that teachers do have strategies that they use to ensure progress is made with the teaching and learning in their classes. The strategies that were indicated include group discussion and peer tutoring to ensure comprehension. In addition, teachers used code switching and elaboration to make their points clear especially when teaching difficult concepts. Some participants indicated that they conveyed questions orally to support learners with reading difficulties. Furthermore, individualised attention and teaching of learners which is often accompanied by adaptation, adaption, and modification of lessons improve learner engagement. Employing role playing, songs and rhymes have been found to be useful strategies to facilitate learning with younger children. Using resources for a varieties of communication modes and learning styles such as visual aid alongside written materials have been found effective, although resources are not always available making the process tedious.

\section{Resources required to facilitate learning in multilingual classes}

The participants indicated that they and other teachers in similar multilingual contexts are not specifically prepared to teach in multilingual contexts. However, given the nature of the job, teachers often have to improvise. The participants identified two main components: classroom-based resources and training-based teacher support.

With classroom-based resources, participant highlighted having textbooks (including dictionaries, posters, charts, flashcards, kinaesthetic resources), equipment such as overhead projectors and access to technology to enhance teaching. Other resources required include

CONTACT: Margaret Funke Omidire Funke.omidire@up.ac.za ORCID: https://orcid.org/0000-0002-5784-7734 
Volume 2, 2020

for all learners to have access to a glossary of terms and keywords in multiple languages. All the teachers included the need for smaller class sizes.

In respect of training-based teacher support, more than half of the participants indicated that they experience limited support from the school and would appreciate more opportunities for relevant in-service training and workshops focused on appropriate intervention strategies. The participants also reiterated the need for concerted involvement of school-based support team on issues relating to multilingualism and language in education.

\section{Discussion}

In answering the question of what constitutes the derived knowledge and experience of teachers in the context of the study, the participants used their personal experiences to elaborate on what they deemed worth knowing in terms of multilingual classes and lessons to be learned from them. Teachers were adequately knowledgeable in terms of concept clarification and general understanding of language in education. This is a first step in being able to recognise the depth of the challenges faced by both teachers and learners. Inability to grasp the concepts could be construed as the teachers, not in tune with the challenges faced by their learners and resultant barriers language posed in the teaching and learning of the learners. A central theme from the experience of the participants is the acknowledgement by the majority of them that the pre-service training they had received did not adequately prepare them, in terms of pedagogy for working in a multilingual classroom. This is currently a recurring theme as identified by Finch, Theakston and Serratrice, (2018). Furthermore, the participants believe that the effects of teaching and learning in multilingual classrooms without the correct resources and training could result in barriers to learning. This concurs with several studies over the years (Finch, Theakston and Serratrice, 2018). There is a need to change the narrative around language, language in education, multilingualism and multilingual education.

It is evident in the experience of the participants that there are multiple challenges associated with teaching in multilingual classes. This is significant because the importance of information gathering from those directly affected is that policymakers and researchers are able to see through the eyes of teachers and establish the necessary step to support them based on their experience and perception of need. Previous studies also highlight challenges of teaching in these contexts and effects on learner achievement (Monar-Lopez and Villar, 2018).

Furthermore, the participants noted that there were benefits of teaching and learning in multilingual classes. Many studies have also shown the benefits of being multilingual and learning in multilingual contexts (Finch, Theakston and Serratrice, 2018; Monar-Lopez and Villar, 2018). Aluko (2019) used affordances theory to elaborate on the opportunities and possibilities that exist if the interaction between the teachers, learners and the multilingual setting is optimised. The interaction and relevant shared experiences within the learning environment is also supported by the sociocultural theory. The participants shared a range of

CONTACT: Margaret Funke Omidire Funke.omidire@up.ac.za ORCID: https://orcid.org/0000-0002-5784-7734

This work is licensed under a Creative Commons Attribution 4.0 International License. 
Volume 2, 2020

strategies that they used to bridge the gap in learning and reduce the incidence of language being a barrier to learning. The novel ideas used by the participants in the study also shed light on possible approaches that could be implemented effectively in classes. From their description, it is evident some of the strategies required further enhancement and structure to be effective. Further research and development of frameworks for the use of code-switching, group discussion and peer tutoring and integrating these into the curriculum specifically designed for multilingual classrooms should be conducted. Daly and Sharma, (2018) acknowledge additional language as resource for learning and the difference multilingual education can make in classes with diverse learners as in a multilingual setting, the majority of the time could be spent by the learners simply attempting to make sense of the questions asked or instructions given by the teachers; and in terms of communicating their ideas.

Teachers' attitude and language ideologies could affect the course of teacher-learner relationship and the learning process as found by Catalano, Reeves and Wessels (2018). The participants' actions and level of engagement to support learners were directly dependent on their beliefs about language and language in education. Finch, Theakston and Serratrice (2018) also found that the attitude of teachers could affect the quality of teaching. A basic programme for improving the quality of teaching in these contexts could start with an awareness campaign aimed at producing a shift in attitude to a more positive stance towards the use of home languages for learning.

Notable among the knowledge shared by the participants is the nature of the resources and support required to optimise learning in multilingual classes. While in the short term, it might be difficult to resolve challenges such as large class sizes, a concerted effort to provide other resources such as books, and multilingual glossary of terms is a start. The specifics in terms of required training and professional development should be properly mapped in addition to intervention study into the efficacy and impact of the strategies deemed effective by the teachers (Finch, Theakston and Serratrice, 2018). Teacher education programmes in higher institutions of learning need to be revised to accommodate new thinking regarding multilingualism and teaching in multilingual classrooms and conventional ideas regarding learning, including language and other subjects have to be challenged while other novel ideas should be developed.

\section{Conclusion}

The findings show that the experiences of teachers and their derived knowledge of multilingualism varied. It is, however, significant that teachers' perspectives and knowledge on the matters of teaching and learning in multilingual classes will inform our knowledge on the pathways for promoting learning, learner wellbeing and facilitating improved achievement in multilingual classes. The paper adds to the body of knowledge by providing insights from teachers' and adding teachers voices to debate around multilingualism and language in education. This is a first step in gaining traction on the subject. The challenges highlighted by

CONTACT: Margaret Funke Omidire Funke.omidire@up.ac.za ORCID: https://orcid.org/0000-0002-5784-7734 
Volume 2, 2020

teachers also provide information on the specifics researchers and policymakers need to focus attention on when developing support strategies and bridging the gaps in the quest for multilingual education. Importantly, the study affirms that there are significant benefits of multilingualism as identified by the participants that could positively improve multilingual education given the appropriate support.

ORCID

https://orcid.org/0000-0002-5784-7734

\section{References}

Agirdag, O. 2014. The long-term effects of bilingualism on children of immigration: Student bilingualism and future earnings. International Journal of Bilingual Education and Bilingualism, 17(4), 449-464.

Aluko F. R. 2019. Multilingualism as a resource for teaching and learning: Overcoming persistent challenges. In Omidire, M.F. (Ed) Multilingualism in the classroom: Teaching and learning in a challenging context. p. 2-9. Cape Town: UCT Press

Bo, C. 2015. Social Constructivism of Language and Meaning. Croatian Journal of Philosophy, 15(43), 87-113.

Brutt-Griffler, J. 2017. English in the multilingual classroom: implications for research, policy and practice. PSU Research Review, 1(3), 216-228 DOI 10.1108/PRR-10-2017-0042

Catalano, T., Reeves, J., \& Wessels, J. 2018. The Soccer Field, It Has Dirt: A Critical Analysis of Teacher Learners in Contact With Emergent Multilingual Students, Critical Inquiry in Language Studies, 15:1, 1-20, DOI: 10.1080/15427587.2017.1329626

Chikiwa, C., \& Schäfer, M. 2018. Promoting Critical Thinking in Multilingual Mathematics Classes through Questioning. EURASIA Journal of Mathematics, Science and Technology Education, 14(8), 1-15.

Chostelidou, D., Griva, E., \& Tsakiridou, E. 2015. Language learners' skills and strategies: Assessing academic needs in a multilingual context. Procedia-Social and Behavioral Sciences, 191, 1472-1478.

Clegg, J., \& Simpson, J. 2016. Improving the effectiveness of English as a medium of instruction in sub-Saharan Africa. Comparative Education, 52(3), 359-374, DOI: 10.1080/03050068.2016.1185268.

CONTACT: Margaret Funke Omidire Funke.omidire@up.ac.za ORCID: https://orcid.org/0000-0002-5784-7734 
Volume 2, 2020

Daly, N. \& Sharma, S. 2017. Motivation and the reciprocal nature of professional learning between New Zealand teachers working with untrained India teachers, Waikato Journal of Education, 22(1).

Desai, Z. 2016. Learning through the medium of English in multilingual South Africa: enabling or disabling learners from low income contexts? Comparative Education, 52(3), 343-358, DOI: 10.1080/03050068.2016.1185259

Dryden-Peterson, S. 2015. The educational experiences of refugee children in countries of first asylum. Washington, DC: Migration Policy Institute.

Finch, K., Theakston, A., \& Serratrice, L. 2018. Teaching modern foreign languages in multilingual classrooms: an examination of Key Stage 2 teachers' experiences, The Language Learning Journal, 1-15. DOI: 10.1080/09571736.2018.1448432

García, O., \& Kleyn, T. (Eds.). 2016. Translanguaging with multilingual students: Learning from classroom moments. London, UK: Routledge

García, O., \& Sylvan, C. E. 2011. Pedagogies and practices in multilingual classrooms: Singularities in pluralities. The Modern Language Journal, 95(3), 385-400.

Makgato, M. 2014. The use of English and code switching in the teaching and learning of technology in some schools in Eastern Cape Province, South Africa. Mediterranean Journal of Social Sciences, 5(23), 933-940.

Marin, L. M., \& Halpern, D., F. 2011. Pedagogy for developing critical thinking in adolescents: Explicit instruction produces greatest gains. Thinking Skills and Creativity, 6(1), 1-13.

Monar-Lopez, A., \& Villar M. 2018. Studies in Second Language Acquisition. 40(4). Cambridge, UK: Cambridge University Press.

Mwelwa, J. M. 2016. The didactics of an English-Bemba anthology of oral traditional narratives in the Zambian Grade Ten literature class. (Unpublished doctoral dissertation). University of South Africa, South Africa.

Ndofirepi, A. P. 2012. Quality education in Africa: Introducing philosophy for children to promote open-mindedness. Africa Education Review, 9(1), 526-540.

Omidire, M. F., Bouwer, A. C., \& Jordaan, J. C. 2011. Addressing the assessment dilemma of additional language learners through dynamic assessment. Perspectives in Education, 29(2), 48-60.

CONTACT: Margaret Funke Omidire Funke.omidire@up.ac.za ORCID: https://orcid.org/0000-0002-5784-7734

This work is licensed under a Creative Commons Attribution 4.0 International License. 
Volume 2, 2020

Omidire, M.F. 2019. Embracing multilingualism as a reality in classrooms. In Omidire, M.F. (Ed) Multilingualism in the classroom: Teaching and learning in a challenging context. pg. 29. Cape Town: UCT Press

Philpo, J. 2015. Constructivism: Its implications for language teaching and second-language acquisition. Retrieved from http://hdl.handle.net/20.500.11810/4616. Accessed on 20 August 2019.

Philipsen, B., Tondeur, J., Roblin., N.P.R., Silke, V., \& Zhu, C. 2019. Improving teacher professional development for online and blended learning: a systematic meta-aggregative review. Education Tech Research Dev, 67, 1145-1174 https://doi.org/10.1007/s11423-01909645-8.

Portolés, L., \& Martí, O. 2020. Teachers' beliefs about multilingual pedagogies and the role of initial training. International Journal of Multilingualism, 17(2), 248-264, DOI: 10.1080/14790718.2018.1515206.

Pretorius, S. G. 2014. Educators' perceptions of school effectiveness and dysfunctional schools in South Africa. Journal of Social Sciences 40(1), 51-64.

Prinsloo, C., H., Ramani, E., Joseph, M., Mashatole, A., Lafon, M., \& Webb, V. 2015. An interprovince study of language and literacy paradigm and practices in foundation phase classroom in Limpopo and Gauteng. Pretoria: Human Sciences Research Council.

Ouane, A., \& Glanz, C. (Eds.). 2011. Optimising learning, education and publishing in Africa: the language factor. A review and analysis of theory and practice in mother-tongue and bilingual education in Sub-Saharan Africa. Hamburg: UNESCO/Tunis Belvedere: ADEA.

Scott, C. L. 2015. The futures of learning 3: What kind of pedagogies for the $21^{\text {st }}$ Century? UNESCO Education Research and Foresight, Paris. (Education Research Foresight Working Papers Series, No. 15). Retrieved from https:unesdoc.unesco.org/ark:48223/pf0000243126. Accessed on 20 March 2019.

Sibomana, E. 2020. Transitioning from a local language to English as a medium of instruction: Rwandan teachers' and classroom-based perspectives. International Journal Of Bilingual Education And Bilingualism,1-15 https://doi.org/10.1080/13670050.2020.1749554

Spaull, N. 2013. South Africa's education crisis: The quality of education in South Africa 19942011. Johannesburg: Centre for Development and Enterprise, 1-65.

Spaull, N. 2015. Education quality in South Africa and Sub-Saharan Africa: An economic approach. (Unpublished doctoral thesis), Stellenbosch University, Stellenbosch.

CONTACT: Margaret Funke Omidire Funke.omidire@up.ac.za ORCID: https://orcid.org/0000-0002-5784-7734

This work is licensed under a Creative Commons Attribution 4.0 International License. 
Volume 2, 2020

Thomson, S., Hillman, K., Wernert, N., Schmid, M., Buckley, S., \& Munene, A. 2012. Monitoring Australian Year 4 student achievement internationally: TIMSS and PIRLS 2011.Australia's Perspective. Melbourne: Australian Council for Educational Research.

UNESCO \& UNICEF. 2013. Envisioning Education in the post 2015 development Agenda: Executive Summary. Paris, UNICEF and UNICEF Retrieved from http://en.unesco.org/post2015/sites/post2015/files/post 2015 en web.pdf. Accessed 15 April 2019.

UNESCO. 2016. Education 2030. Incheon Declaration and Framework for Action Towards inclusive and equitable quality education and lifelong learning for all. Paris: UNESCO.

UNESCO. 2016b. If you don't understand how can you learn? Global Education Monitoring Report (Policy 24). PARIS: UNESCO.

Van Staden, S., \& Howie, S. 2010. South African teacher profiles and emerging teacher factors: The picture painted by PIRLS 2006. Reading \& Writing - Journal of the Reading Association of South Africa, 1(1), 47-60.

Vygotsky, L. S. 1978. Mind in society: The development of higher psychological processes. Cambridge, MA: Harvard University Press.

Weber, J. J. 2014. Flexible multilingual education: Putting children's needs first. Multilingual Matters, 38, insert pages.

Wei, L. 2011. Moment analysis and translanguaging space: Discursive construction of identities by multilingual Chinese youth in Britain. Journal of Pragmatics, 43: 1222- 1235.

CONTACT: Margaret Funke Omidire Funke.omidire@up.ac.za ORCID: https://orcid.org/0000-0002-5784-7734 